\title{
Bilateral endogenous Candida albicans subretinal abscess with suspected mixed bacterial infection
}

\author{
This article was published in the following Dove Press journal: \\ Clinical Ophthalmology \\ 21 October 2014 \\ Number of times this article has been viewed
}

\author{
Yusuke Arai' \\ Yukihiro Sato' \\ Atsushi Yoshida' \\ Hidetoshi Kawashima' \\ Toshikatsu Kaburaki \\ Harumi Gomi ${ }^{3}$ \\ 'Department of Ophthalmology, \\ Jichi Medical University, Tochigi, Japan; \\ ${ }^{2}$ Department of Ophthalmology, \\ The University of Tokyo, Graduate \\ School of Medicine, Tokyo, Japan; \\ ${ }^{3}$ Center for Clinical Infectious \\ Diseases, Jichi Medical University, \\ Tochigi, Japan
}

Correspondence: Yusuke Arai

Department of Ophthalmology, Jichi Medical University, Shimotsuke,

33। I-I Yakushiji, Tochigi 329-0498, Japan

$\mathrm{Tel}+8 \mathrm{I} 285587382$

Fax +8I 285448365

Email r1003ya@jichi.ac.jp
Purpose: Candida albicans subretinal abscess is extremely rare. To our knowledge, only one unilateral case has been reported. Herein, we report one bilateral case. Mixed bacterial infection was also suspected based on broad-range real-time polymerase chain reaction.

Methods: A 64-year-old man being treated with oral corticosteroids for interstitial pneumonia visited us for visual loss in the left eye. Best corrected visual acuity (BCVA) was 20/20 in the right eye and $8 / 200$ in the left eye. Funduscopy revealed round yellowish-white subretinal lesions with retinal hemorrhage in both eyes.

Results: Broad-range polymerase chain reaction of the vitreous fluid from the left eye showed a high copy count of bacterial 16s ribosome RNA. Despite large doses of antibiotics, the abscess expanded and vision decreased to light perception in the left eye. Exenteration of the left eye was performed followed by microscopic examination showing Gram-negative bacilli, and C. albicans was also cultured. Antibiotics and the maximum doses of antifungal drugs were administered. However, the abscess in the right eye expanded, and BCVA decreased to 2/200. Vitrectomy and silicone oil tamponade were performed. Vitreous fluid culture revealed C. albicans. At 16 months follow-up, BCVA was stable at 4/200 with healing of the subretinal abscess under silicone oil.

Conclusion: Since C. albicans subretinal abscess is extremely rare and there was a concurrent mixed bacterial infection, diagnostic procedures in our bilateral case were more complicated than usual. C. albicans infection should be included in the differential diagnosis of subretinal abscesses.

Keywords: Candida albicans, subretinal abscess, mixed infection

\section{Introduction}

Endogenous fungal endophthalmitis first results in the formation of infectious lesions in the choroid through fungemia, followed by invasion of the retina. It then disseminates from the retina to the vitreous cavity, and induces marked vitreous opacity and traction retinal detachment in severe cases. ${ }^{1}$ In other words, fungal infections usually disseminate vertically, and thus rarely form a subretinal abscess. Conversely, if an infection progresses horizontally under the sensory retina or the retinal pigment epithelium, a subretinal abscess will form, and the vitreous cavity will not become cloudy until the advanced stage. Aspergillus has been identified as the most frequent fungal cause of subretinal abscess, ${ }^{2}$ while Candida albicans subretinal abscess is extremely rare. To our knowledge, only one unilateral case has been reported. ${ }^{3}$ We had an experience with a patient with bilateral subretinal abscesses. C. albicans was cultured from surgical specimens, and mixed bacterial infection was also suspected based on broad-range real-time polymerase chain reaction (PCR).,

\section{Case report}

A 64-year-old man visited Jichi Medical University Hospital complaining of left eye visual loss and floaters in the right eye. He was referred to us by the Department 
of Allergy and Rheumatism of our hospital, having been administrated $40 \mathrm{mg}$ of oral prednisolone for more than 6 weeks as treatment for interstitial pneumonia accompanying rheumatoid arthritis. His medical history included metastatic rectal cancer, intestinal obstruction, and pericarditis.

Best-corrected visual acuity (BCVA) was 20/20 in the right eye and $8 / 200$ in the left eye. Funduscopy revealed round yellowish-white subretinal lesions with retinal hemorrhage in both eyes (Figure 1A and B).

Laboratory studies showed elevated titers of the antiToxoplasma, anti-Herpes simplex virus IgG, anti-Herpes simplex virus IgM, and anti-cytomegalovirus IgG antibodies, as well as low cell lymphocyte and CD4-positive lymphocyte counts. In contrast, the white blood cell count, C-reactive protein, and $\beta$-D glucan levels were not increased.

No abnormalities were noted on blood culture or wholebody contrast computed tomography.

Administration of oral anti-Toxoplasma (acetylspiramycin 1,800 $\mathrm{mg} /$ day) and anti-viral drugs (valganciclovir $1,800 \mathrm{mg} /$ day) was initiated. However, the lesions expanded in both eyes.

Diagnostic vitrectomy of the left eye was performed 4 weeks after the initial examination. Although the vitreous fluid sample was subjected to broad-range PCR, multiplex PCR, and other culture tests, no positive results were obtained.

Based on the fundus findings, broad-spectrum antibiotic treatment (imipenem/cilastatin 2,000 mg/day and amikacin $600 \mathrm{mg} /$ day) was initiated, under suspicion of bacterial infections including Nocardia. However, the lesions did not improve. Thus, antibiotics (ceftazidime $2 \mathrm{mg}$, vancomycin $1 \mathrm{mg}$, and voriconazole $0.05 \mathrm{mg} / 0.1 \mathrm{~mL}$ each) were injected

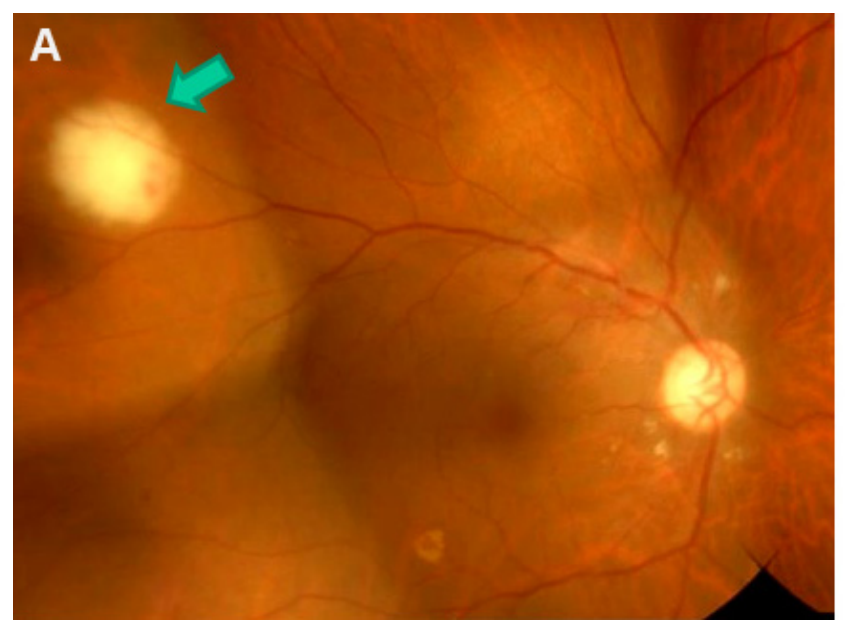

into the vitreous cavity 6 weeks after the initial examination, and a vitreous tap was simultaneously performed. Broadrange PCR of the vitreous fluid showed $3.75 \times 10^{4}$ copies/ $\mathrm{mL}$ of bacterial $16 \mathrm{~s}$ ribosomal RNA, strongly suggesting bacterial infection. Albeit with antibiotic treatment, the lesions further deteriorated BCVA to light perception (Figure 2A).

Seven weeks after the initial examination, exenteration of the left eye was performed. Immediately after the operation, microscopic observation of the removed and then Gramstained tissue revealed Gram-negative rods. However, no bacteria corresponding to these organisms grew in culture of either the removed tissue or vitreous fluid, and only C. albicans was isolated. Sheep blood agar and chocolate agar were used for culture and intubated with 5\% carbon dioxide at $35^{\circ} \mathrm{C}$ for 48 hours. The picture of the Gram-stained sample was taken from this culture (Figure 2B, left). Then, the colonies grown on these cultures were harvested and cultivated on the CHROMagar ${ }^{\circledR}$ for identification. The picture of the agar plate shows the colonies that are green in color on the CHROMagar $^{\circledR}$ suggesting the species of $C$. albicans based on its color (Figure 2B, right).

Based on these findings, mixed bacterial and fungal infection was considered, and simultaneous systemic administrations of antibiotics (levofloxacin $500 \mathrm{mg} /$ day) and maximum-dose antifungal agent (fosfluconazole $600 \mathrm{mg} /$ day) were initiated. In addition, antibiotics (ceftazidime $2 \mathrm{mg}$, vancomycin $1 \mathrm{mg}$, and voriconazole $0.05 \mathrm{mg} / 0.1 \mathrm{~mL}$ each) were injected into the vitreous cavity of the right eye three times from 8 weeks to 10 weeks after the initial examination. Broad-range PCR of the vitreous fluid obtained from simultaneous vitreous tap 8 weeks after the initial examination

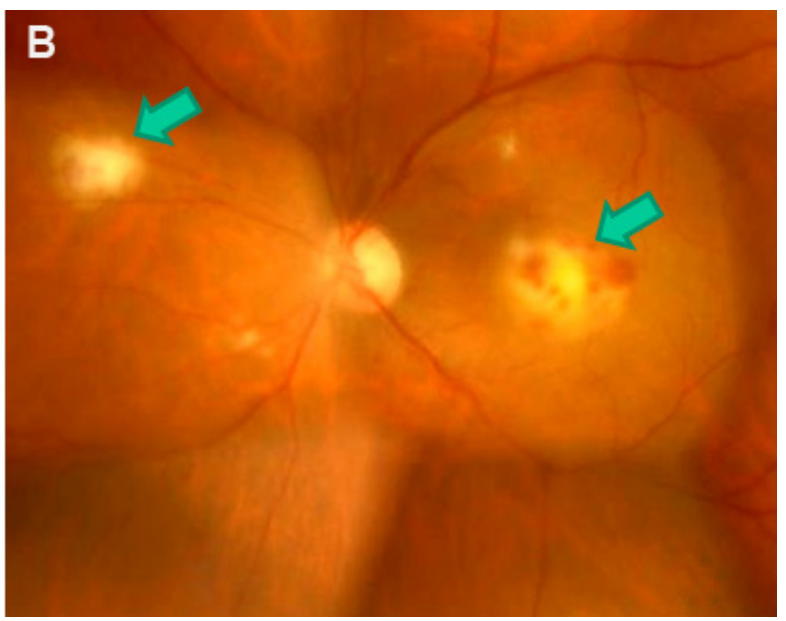

Figure I Fundus photographs obtained at the initial examination.

Note: Yellowish-white subretinal lesions with retinal hemorrhage (arrows) can be seen in both the right (A) and the left (B) eye. 


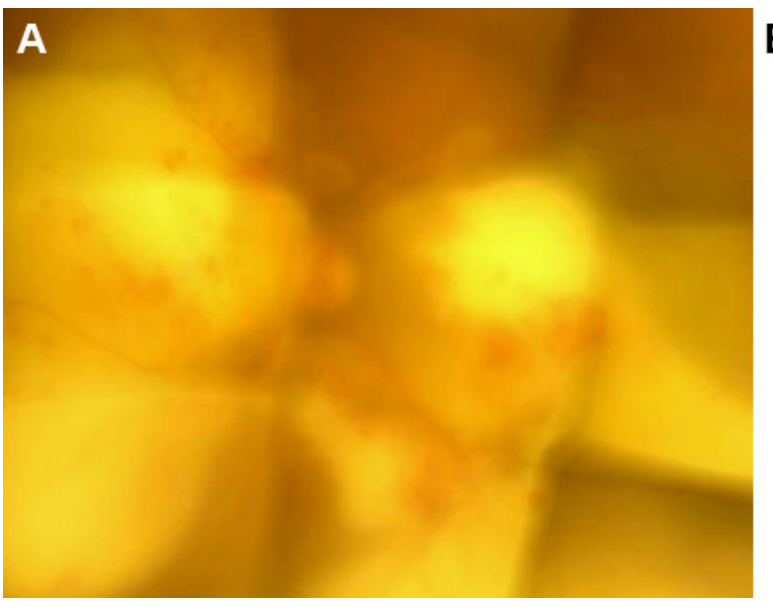

\section{B}

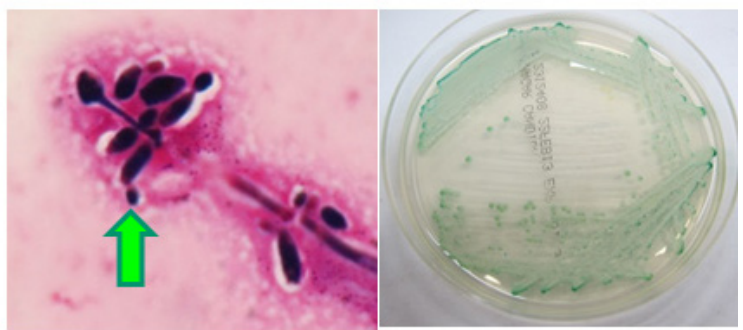

Figure 2 Fundus photograph of the left eye, and results of bacteriologic examinations.

Notes: (A) Left fundus 7 weeks after the initial examination. The visual acuity was light perception. (B) Results of samples collected on exenteration of the left eye. The left photograph shows the Gram-stain by microscope with high power field $(\times 1,000$ with oil immersion). Pseudohyphae with condiospores grew by culture of the samples taken from the left eye exenteration (arrow). The right photograph shows the green color colonies consistent with Candida albicans on $\mathrm{CHROMagar}^{\circledR}$.

revealed $7.19 \times 10^{4}$ copies $/ \mathrm{mL}$ of bacterial $16 \mathrm{~s}$ ribosomal RNA, and $1.85 \times 10^{5}$ copies $/ \mathrm{mL}$ of fungal 28 s ribosomal RNA, suggesting a fungus-dominant mixed infection.

The subretinal abscess in the right eye expanded, approaching the central fovea (Figure 3A), and BCVA decreased to $2 / 200$. Vitrectomy combined with cataract surgery and silicone oil injection was performed 10 weeks after the initial examination. C. albicans was detected by vitreous fluid culture. Systemic administration of the antifungal agent was continued after surgery, and the lesions healed under silicone oil (Figure 3B). The fundus had stabilized 1 year and 4 months after the initial examination, and BCVA was maintained at $4 / 200$.

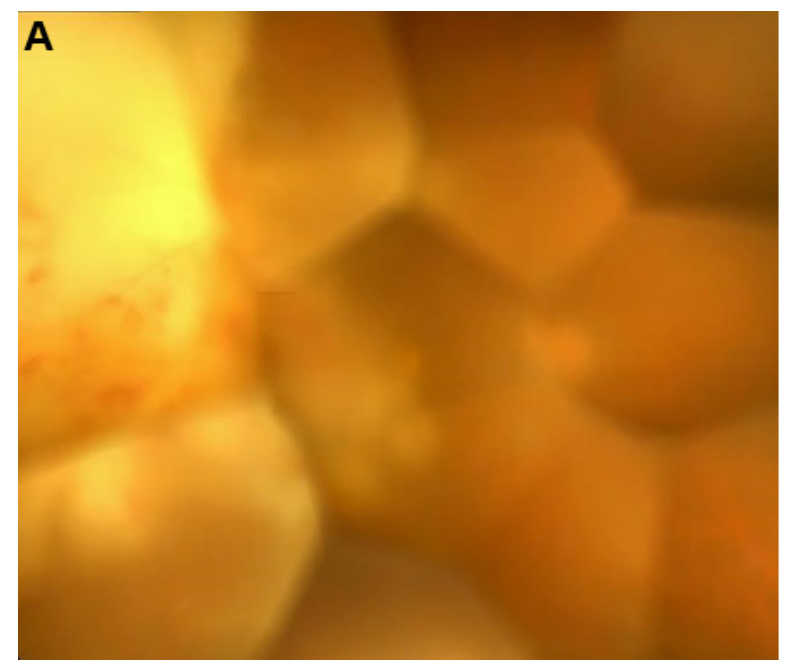

\section{Discussion}

Subretinal abscess formation in endogenous endophthalmitis is rare. Since the most frequent causative bacterium is reportedly Nocardia, ${ }^{2}$ we considered Nocardia infection in our case. Aspergillus was identified as the most frequent fungal cause of subretinal abscess. ${ }^{2}$ Rao and Hidayat reported the histopathological features of 13 cases with Aspergillus and 12 cases with Candida endophthalmitis. ${ }^{6}$ In their report, the authors stated that Aspergillus was most abundantly seen at the subretinal and subretinal pigment epithelium regions, whereas Candida was noted primarily in the vitreous. ${ }^{6}$

To our knowledge, only one unilateral case of C. albicans subretinal abscess after liver transplantation has been

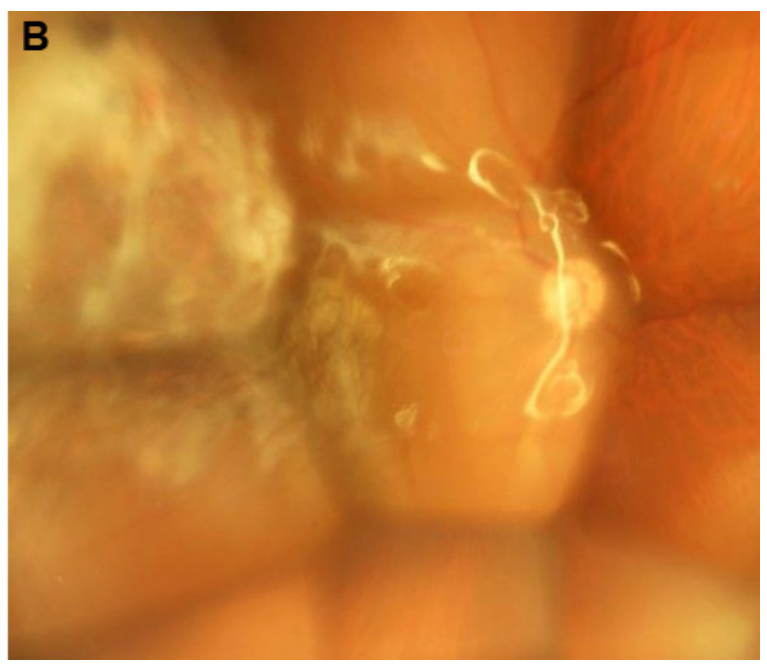

Figure 3 Fundus photographs of the right eye.

Notes: (A) Ten weeks after the initial examination. The subretinal abscess expanded, approaching the central fovea, and visual acuity was $2 / 200$. (B) Twelve months after combined cataract and vitreous surgeries. The lesions healed under silicone oil, and visual acuity was 4/200. 
reported. ${ }^{3}$ Thus, our patient may be the second $C$. albicans subretinal abscess case to be reported.

Our patient was treated with high-dose prednisolone $(0.7 \mathrm{mg} / \mathrm{kg}$, more than 6 weeks) for interstitial pneumonia and could well have been immunocompromised. Whole-body examination was performed, but no infectious lesions were found other than those in the eyes. Thus, detection of the fungus in the intraocular tissue and vitreous fluid was necessary to make a definite diagnosis. The frequency of fungal isolation and culture from vitreous fluid is reportedly $42 \%,{ }^{7}$ but the frequency may be lower when lesions are limited to the subretinal space. Fungal identification by direct biopsy of a subretinal abscess using a vitreous cutter has been reported, but proliferative vitreoretinopathy developed from the biopsied site. ${ }^{8}$ Another report described successful transscleral drainage of a subretinal abscess, ${ }^{9}$ but this procedure is only applicable when the lesion is present in the peripheral fundus. There are as yet no safe and reliable methods for direct biopsy of a subretinal abscess. In our case, BCVA of the left eye deteriorated to light perception despite systemic and intravitreal administration of antibiotics, and the lesion was not present in the peripheral fundus. Thus, we performed exenteration of the left eye.

The blood $\beta$-D glucan-positive rate was reported to be $95 \%$ in fungal endophthalmitis patients. ${ }^{10}$ However, the blood $\beta$-D glucan level was not elevated in our patient, making the diagnosis more difficult. This may be due to the limited location of fungal infection exclusively to the eyes.

We also performed broad-range real-time PCR and multiplex PCR tests. ${ }^{4,5}$ Diverse exogenous micro-organisms causing ocular inflammatory diseases can be exhaustively screened by these tests within a short time. ${ }^{4,5}$ In our patient, vitreous fluid obtained on diagnostic vitrectomy of the left eye performed 4 weeks after the initial examination was tested, but positive results were not obtained. This may be due to localization of the abscess in the subretinal space and poor dissemination of the causative agents to the vitreous cavity. On vitreous tap of the left eye 6 weeks after the initial examination, only bacteria were detected by broad-range
PCR, and the reason for this was unclear. In contrast, the vitreous tap of the right eye 8 weeks after the initial examination was positive for both bacteria and fungi. Considering that no safe and reliable biopsy method is available for subretinal abscesses, further improvements in sensitivity and specificity of PCR tests are needed.

We have described herein a rare case of bilateral endogenous $C$. albicans subretinal abscesses in which mixed bacterial infection was suspected and made the diagnosis more complicated. C. albicans infection should be included in the differential diagnosis of subretinal abscesses.

\section{Disclosure}

The authors report no conflicts of interest in this work.

\section{References}

1. Ishibashi Y. [Proposed classification of stages of endogenous fungal endophthalmitis.] Jpn J Clin Ophthalmol. 1993;47(4):845-849. Japanese [with English abstract].

2. Harris EW, D'Amico DJ, Bhisitkul R, Priebe GP, Petersen R. Bacterial subretinal abscess: a case report and review of the literature. $\mathrm{Am} J$ Ophthalmol. 2000;129(6):778-785.

3. Kaburaki T, Takamoto M, Araki F, et al. Endogenous Candida albicans infection causing subretinal abscess. Int Ophthalmol. 2010;30(2):203-206.

4. Sugita S, Ogawa M, Shimizu N, et al. Use of a comprehensive polymerase chain reaction system for diagnosis of ocular infectious diseases. Ophthalmology. 2013;120(9):1761-1768.

5. Ogawa M, Sugita S, Watanabe K, Shimizu N, Mochizuki M. Novel diagnosis of fungal endophthalmitis by broad-range real-time PCR detection of fungal 28S ribosomal DNA. Graefes Arch Clin Exp Ophthalmol. 2012;250(12):1877-1883.

6. Rao NA, Hidayat AA. Endogenous mycotic endophthalmitis: variation in clinical and histopathologic changes in Candidiasis compared with Aspergillosis. Am J Ophthalmol. 2001;132(2):244-251.

7. Hatano H, Inoue K, Matoba H, et al. [Endophthalmitis in Japan - a nationwide study with reference to type and etiology.] Acta Soc Ophthalmol Jpn. 1991;95(4):369-376. Japanese.

8. Matthews BJ, Partridge D, Sheard RM, Rennie IG, Mudhar HS. A unique case of phaeohyphomycosis subretinal abscess in a patient with arthropathy and lung pathology. Indian J Ophthalmol. 2013;61(12):763-765.

9. Durkin SR, Muecke JS. Successful treatment of a large choroidal abscess in an immunocompetent child. Graefes Arch Clin Exp Ophthalmol. 2007;245(8):1233-1235.

10. Takebayashi H, Mizota A, Tanaka M. Relation between stage of fungal endophthalmitis and prognosis. Graefes Arch Clin Exp Ophthalmol. 2006;244(7):816-820.
Clinical Ophthalmology

\section{Publish your work in this journal}

Clinical Ophthalmology is an international, peer-reviewed journal covering all subspecialties within ophthalmology. Key topics include: Optometry; Visual science; Pharmacology and drug therapy in eye diseases; Basic Sciences; Primary and Secondary eye care; Patient Safety and Quality of Care Improvements. This journal is indexed on Submit your manuscript here: http://www.dovepress.com/clinical-ophthalmology-journal

\section{Dovepress}

PubMed Central and CAS, and is the official journal of The Society of Clinical Ophthalmology (SCO). The manuscript management system is completely online and includes a very quick and fair peer-review system, which is all easy to use. Visit http://www.dovepress.com/ testimonials.php to read real quotes from published authors. 